Reproduced with permission of the copyright owner. Further reproduction prohibited without permission.

Address correspondence to: James H. Conway, MD, FAAP, Associate Professor of Pediatrics, Division of Pediatric Infectious

Diseases, University of Wisconsin School of Medicine and Public Health, 600 Highland Ave. H4/450 CSC, Madison, WI 53792; fax:

608-263-6210; jhconway@ pediatrics.wisc.edu.

Dr. Conway and Dr. Green have disclosed no relevant financial relationships. 
In this article, we review the process through which vaccines are developed, brought to market, and reviewed for recommendations, as well as discuss issues related to safety monitoring. We discuss the current system for funding and providing vaccines to individuals and examine factors that influence pediatric immunization rates and lead to disparities in coverage. We conclude with policy recommendations that address the need to improve immunization coverage rates in the United States.

\section{THE LIFE OF A VACCINE}

The development of vaccines is an expensive and complicated process. Unlike most pharmaceuticals, which are created to treat medical conditions, these biological products are largely designed for administration to healthy individuals. They undergo rigorous clinical trials to ensure safety and efficacy in providing immunity against infectious diseases. In addition, they must be tested in conjunction with the concomitant administration of other routine vaccines to prove that there is neither blunting of the immune response to any of the antigens, nor additive side effect issues.

All documentation related to the production process and results of clinical trials is submitted to the Food and Drug Administration (FDA) for a Biologics License Application. The Vaccines and Related Biological Products Advisory Committee (VRBAC) reviews the relevant research and advises the FDA. The FDA grants licensure based on the recommendations by the VRBAC and its determination that the vaccine is efficacious and safe. ${ }^{7,8}$

Simultaneously, or shortly thereafter, the Advisory Committee on Immunization Practices (ACIP) also considers the vaccine. The ACIP is a committee appointed by the Secretary of the Department of Health and Human Services. It is made up of 15 representatives who are experts from a variety of fields, including public health and medicine, as well as consumers and economists. Efforts are made to balance the membership geographically, racially, by gender, and area of expertise. There are also eight ex officio members representing federal agencies and 26 non-voting liaisons from organizations involved in immunization programs or vaccine development. Monitoring for potential conflicts of interest is strict. ${ }^{8}$

The ACIP reviews not only the materials submitted to the FDA but all pertinent information about a particular disease and vaccine(s), including epidemiologic data, published scientific literature, economic analyses, and expert opinions. Based on all this information, the ACIP makes recommendations for each vaccine, stipulating the patient population and conditions for routine administration. These recommendations are issued initially as provisional guidelines and they become official Centers for Disease Control and Prevention (CDC) policy once they are published in the Mortality and Morbidity Weekly Report (MMWR). ${ }^{8}$

It is common for the ACIP's recommendations to differ from the FDA-approved license for a vaccine. Recent examples include the guidelines for rotavirus and herpes zoster vaccines. $9^{9},{ }^{10}$ Updated recommended immunization schedules are published annually by the CDC and are usually supported by identical schedules from the American Academy of Pediatrics (AAP) and American Academy of Family Physicians (AAFP). ${ }^{11,12}$ 
The proper administration of vaccines and post-licensure monitoring of vaccine safety is critical to the national immunization program. The National Childhood Vaccine Injury Act of 1986 (NCVIA) established rules for record keeping and consent, requiring the distribution of Vaccine Information Statements (VIS) forms. The NCVIA also requires providers to report adverse events to the Vaccine Adverse Events Reporting System (VAERS), although any individual can voluntarily report. These reports are investigated, tabulated, and used as a sentinel system to identify safety issues with individual vaccines. Numerous other agencies and programs participate in vaccine safety monitoring, including the Vaccine Safety Datalink, Clinical Immunization Safety Network, and the Brighton Collaboration. ${ }^{7,13}$ The $\mathrm{ACIP}$ and the CDC also periodically issue general guidelines for all components of immunization practice to ensure that providers are following proper procedures. ${ }^{13}$

The National Vaccine Injury Compensation Program (VICP) was also established by the NCVIA. This is a no-fault system for people to collect compensation for injuries thought to be caused by vaccines. The VICP is funded by tariffs that are added to the sale of every dose of vaccine sold in the US. The program is an alternative to civil litigation, and no evidence of negligence needs to be proven to receive monetary compensation. Each case is adjudicated through the US Court of Federal Claims. ${ }^{7,13}$

\section{IMMUNIZATIONS IN THE US}

As new vaccines are developed and added to the routinely recommended immunization schedule, the overall cost to immunize each child has increased dramatically. In 1987, public sector patients could receive their entire immunization series for $\$ 37$, while the pricing in the private sector was about $\$ 116 .{ }^{14}$

Today, the basic immunization series without the human papillomavirus (HPV) vaccine is $\$ 900$ in the public sector and $\$ 1,285$ in the private sector. The addition of HPV for teenage girls adds $\$ 317$ and $\$ 391$ in costs in the public and private sector, respectively. Annual influenza vaccinations over the first 18 years of life add approximately $\$ 165$ for public sector patients and nearly $\$ 200$ for those in the private sector. In all, completing the routine recommended immunization schedule for a female during her first 18 years of life costs $\$ 1,382$ in the public sector and $\$ 1,876$ using private-sector pricing. ${ }^{15}$

In general, insurers who cover vaccines for individual consumers add each new vaccine to their coverage plan once it is officially recommended for routine administration by the ACIP. The ACIP holds a separate vote deciding which immunizations will be added to the Vaccines for Children (VFC) Program. This allows funding to be provided to public health programs to obtain the necessary vaccines for children covered by state medical assistance programs who would otherwise not be immunized.

Besides the VFC Program, sources of funding in the public sector include local and state public health allocations, block grants under Section 317 of the Public Health Service Act, and since 1997, funds obtained through the State Children's Health Insurance Program (SCHIP). These funds are generally used to target under-insured children who are ineligible 
for Medicaid or VFC programs but are increasingly insufficient as more children lack adequate healthcare coverage. ${ }^{7}$

In addition to the cost of the individual vaccines and the necessary materials for administration, the financial costs of personnel time and vaccine storage have made the financing of immunization programs increasingly challenging for medical care providers. The costs of immunization provision are difficult to estimate. However, one Colorado-based research study suggests that the total costs per vaccine are more than $\$ 10$ in pediatric practices and more than $\$ 5$ per dose in public health agencies. Reimbursement to private providers has been calculated to be $22 \%$ less than actual costs. ${ }^{16}$

Although the majority of children in the US receive their vaccines through private insurance coverage, increasingly large numbers of children depend on public sources to finance their routine immunizations. ${ }^{7}$ As reimbursement rates fail to keep up with the rising cost of providing vaccines, there is concern that even more providers may begin referring patients to public agencies for their vaccines. ${ }^{16-18}$

The Institute of Medicine (IOM) has addressed these developments and convened a Committee on Vaccine Financing to review these issues. The IOM report made several recommendations aimed towards creating financial incentives to protect the existing vaccine supply and to spur the development of new vaccines. These included an insurance mandate requiring all public and private plans to cover all immunization-related costs for routinely recommended vaccines, a system of federal subsidies to enable this to be accomplished, and a process to calculate the societal value of different vaccines for setting fair prices. ${ }^{14}$

\section{TRENDS AND ISSUES WITH IMMUNIZATION PROGRAMS}

Public health officials use the percentage of 2-year-old children (range 19 to 35 months) who have completed the primary immunization series as a benchmark to assess immunization coverage. Younger children are at greater risk for vaccine-preventable diseases, and ensuring that all children receive their vaccinations on time has been selected as a key determinant of the quality of national, state, and local immunization programs. The National Immunization Survey (NIS) is conducted annually by the National Center for Immunizations and Respiratory Diseases (NCIRD) and the National Center for Health Statistics of the CDC. The NIS makes estimates of immunization coverage rates based on a random sampling of households across the United States.

Although trends from the NIS show that overall immunization rates are generally improving from year to year, as the recommended schedule has become increasingly complex and more costly, fewer and fewer children are receiving their vaccines on time. Data from the 2003 NIS indicate that only $18 \%$ of children received all of their vaccinations on time, and $37 \%$ of children were considered undervaccinated for more than 6 of their first 24 months of life. ${ }^{19}$ In addition, minority children tend to have lower immunization rates. Studies using annual data from the NIS have demonstrated that the "gap" between the immunization rates of white and black children widened by an average of $1.1 \%$ each year between 1996 and 2001, and $0.5 \%$ annually between white and Hispanic children over the same time span. ${ }^{20}$ 
Interestingly, although there tends to be an initial 2-year delay when introducing newly recommended vaccines into rural communities, these differences in immunization uptake between children living in urban and rural areas are becoming less apparent. ${ }^{21}$

Another contributing factor to changes in immunization rates over time is the incidence of disease and perceived risk of infection. Economists characterize the demand for vaccines as "prevalence dependent," meaning that as the rates of disease decrease, so do the number of immunizations. The reverse is also true: as disease rates rise (an inevitable consequence of fewer vaccinations), immunization rates may also increase. ${ }^{22}$ Evidence of this phenomenon is found in cities such as Chicago, where a measles outbreak in 1989-1990 led to an increase in measles vaccination rates from $56 \%$ to $70 \% .{ }^{23}$ The increased prevalence of measles also reduced the age at which children received their first measles vaccination. ${ }^{24}$

However, there was little effect on the other recommended vaccines for common childhood diseases. ${ }^{23}$ It appears that changes to risk perception may be disease-specific and that outbreaks might not lead to a overall increase in the demand for other vaccines.

Experts have identified several key factors that lead to underimmunization in children. One such factor is the periodic national vaccine shortages that have occurred over the past 10 years. These shortages tend to disproportionately affect minority children, particularly those of American Indian/Alaska Native background. ${ }^{25}$ Additionally, in medically underserved areas, missed opportunities to immunize lead to delayed vaccine administration. ${ }^{26}$ "Missed opportunities" occur when a child who is age-eligible for a vaccine and has no vaccinerelated medical contraindications does not receive that vaccine during a visit to a medical provider. ${ }^{27}$

Other contributing factors to underimmunization among children include having unmarried parents, belonging to a family with two or more children, and having public insurance or no health care coverage. ${ }^{26}$ Demographic analysis of these undervaccinated children suggests that they are more likely to be black, have a young unmarried mother without a college education, live in an urban area, and live in a household with an annual income near the poverty level. $^{28}$

\section{VACCINE HESITANCY}

Adding to concerns about children who are underimmunized, there is a growing number of parents who choose not to immunize their children. From 1991 to 2004, there has been an increase in the mean state-level rate of non-medical immunization exemptions from $0.98 \%$ to $1.48 \%$, largely driven by a rise in the number of parents who claim philosophical or personal reasons for opting out of vaccines. ${ }^{29}$ There is considerable within- and betweenstate variation in immunization exemption rates. For example, Washington state has an overall nonmedical exemption rate of $6 \%$, but county-level rates vary from $1.2 \%$ to $26 \% .^{29}$

In contrast to the demographic characteristics of undervaccinated children, unvaccinated children 19 to 35 months tend to have parents who are white, married, mothers with a college degree, and are living in households with annual incomes of more than $\$ 75,000 .^{29}$ When surveyed, the parents of unvaccinated children often indicate that they are concerned 
about vaccine safety. They also respond that physicians have little influence over their decisions to immunize. ${ }^{28}$

Parents who have refused some or all immunizations on behalf of their school-aged children report similar concerns about vaccine safety and often believe that their children have little susceptibility to vaccine-preventable infections. They also report a distrust of government, and are skeptical of information from medical or public health sources, preferring to rely on alternative medical professionals. ${ }^{30}$

For parents who are worried about vaccine safety, one of their primary concerns is the purported link between vaccinations and autism. Even though the original, problematic Lancet study linking the measles, mumps, and rubella (MMR) vaccine to autism ${ }^{31}$ has been widely discredited and withdrawn, and a wealth of counterevidence has emerged that demonstrates that there is no association, ${ }^{32}$ the media has continued to portray the autism/ vaccine debate as a source of controversy within the scientific and medical communities. ${ }^{33}$ Despite efforts to provide accurate information for families, the struggle to combat media misinformation continues. ${ }^{34}$

Unfortunately, parental refusal to vaccinate leaves more than just their children at risk for disease, as there is a clear effect on community disease epidemiology as well. In Colorado, children whose parents refused to have them immunized were 22.2 times more likely to develop measles and 5.9 times more likely to contract pertussis compared with children who were immunized. ${ }^{35}$ Because no vaccine protects every recipient, some immunized children will inevitably develop illness during large outbreaks.

In Colorado-based outbreaks between 1987-1998, schools where immunized children contracted disease had $4.3 \%$ of attendees whose parents had taken an exemption to school immunization requirements, compared with only $1.5 \%$ in schools where no outbreaks occurred. ${ }^{35}$ Clearly, clusters of families that refuse to immunize increase the risk of disease at the family and community levels.

A similar phenomenon has been observed in other developed countries. In the United Kingdom, immunization rates for the measles-mumps-rubella (MMR) combination vaccine reached $91 \%$ in 1998, essentially eliminating measles. As rumors of negative side effects from the MMR vaccine spread widely, immunization rates gradually decreased to below $90 \%$. As a result, measles outbreaks recurred, and eventually the disease became endemic again in the UK. ${ }^{36}$

Experts fear that inequitable access to immunizations, combined with ongoing parental concerns about vaccine safety, and the lack of disease risk perception on the part of some parents will continue to erode US immunization rates. This will potentially result in an increasingly susceptible population, allowing outbreaks to become widespread once again in the US.

Given the dire implications of disease epidemics, the benefits of broad immunization coverage are unquestionable for the vaccine recipient and for society. ${ }^{1}$ One such benefit extends to those children who cannot, for a variety of reasons, receive immunizations. 
Vaccinating the population widely provides "herd immunity" for vulnerable subgroups that cannot be vaccinated, such as very small infants and children with immune disorders, decreasing the chance of exposure for these susceptible populations. ${ }^{37}$

In addition to imposing individual- and family-level costs, containing outbreaks of vaccinepreventable disease places a strain on the resources of public health departments and other affected organizations. For example, one study conservatively estimated that the state of Iowa's cost for containing three measles cases was at least $\$ 140,000$ and an outbreak in Colorado closed the entire camp, costing the organizers a substantial sum. ${ }^{4,38}$

The broader use of vaccines can also help to reduce disparities in health outcomes. For example, before the routine use of the varicella vaccine, rates of hospitalization for varicella were higher in blacks than in whites. Following the routine implementation of the varicella vaccine in 1995, black/white disparities in hospitalization rates were eliminated, attributable to increases in individual-level immunity and reduced community susceptibility. ${ }^{39}$

Research has also shown that there are spillover benefits from vaccines when just one susceptible population is immunized. After the licensure of the pneumococcal conjugate vaccine in 2000 for children, the invasive pneumococcal rates decreased in children and the elderly (the latter of whom are often in contact with young children). ${ }^{40}$

\section{STRATEGIES FOR INCREASING IMMUNIZATION COVERAGE}

Clearly, improving immunization coverage in children offers benefits to the individual and society. Yet despite these well-documented benefits, immunization rates continually fail to reach optimal levels, even in more developed countries like the US. Much of the problem seems related to disparities in access to care, coupled with missed opportunities to immunize during routine visits to medical providers. But there are also increasingly large segments of the population who choose not to avail themselves of these powerful tools to prevent infection and disease.

Attempts to combat these challenges have included improved insurance coverage and removal of financial barriers, practice improvements, school entry requirements, and better educational information for parents and providers.

Although children living in poverty have had longstanding healthcare coverage through Medicaid, a substantial number of near-poor children were ineligible. This resulted in the creation of the State Children's Health Insurance Program (SCHIP) in 1997, which mandated that state healthcare plans cover the cost and administration of childhood vaccines. In the first 5 years of the program, rates of immunization coverage for poor and near-poor children increased by $11 \%$. However, non-poor immunization rates increased at nearly the same rate, making it difficult to credit SCHIP with any substantial improvements. ${ }^{41}$

Having health insurance does not necessarily guarantee that children will be up-to-date with immunizations. Out-of-pocket expenses can be quite substantial for families with some types of coverage, and subsidizing these costs either partially or fully can potentially increase immunization rates. ${ }^{34,42}$ Another significant barrier to adherence to the required childhood 
immunization schedule is the lack of a usual site for medical care. Children who lack a medical home and do not possess adequate coverage are more likely to be underimmunized and also tend not to be immunized in a timely manner. ${ }^{43}$

There are also provider-level practices that can result in better immunization coverage. The increasing mobility of families and the lack of consistent care sites appear to have negatively affected immunization coverage through "record scatter." ${ }^{4}$ Centralized immunization registries have now become commonplace in many regions of the country and offer the ability to obtain timely documentation of a patient's immunization history. One study found that having immunization records maintained in a central and accessible database was associated with a 50\% increase in children who were up-to-date with their routine immunizations at 24 months. ${ }^{44}$

Researchers project even greater potential improvements in immunization rates when the use of centralized electronic records is coupled with reminder and recall messages for providers and families. ${ }^{34}$

The use of school entry requirements that mandate the receipt of vaccines before attending day care or school has been an important and effective measure in controlling communicable diseases. Although there are no federal statutes that cover school entry requirements, state legislatures implemented laws to prevent contagious diseases such as measles from circulating within schools.

Courts have consistently upheld these rules based on the legal requirement of society to protect individuals from harm. ${ }^{45}$ Many states have also expanded school entry requirements in order to improve immunization rates for less readily transmitted diseases, such as hepatitis B. States with school entry vaccine requirements consistently demonstrate improved immunization rates compared with those without such mandates. ${ }^{34,46}$ These positive effects are found in children regardless of age, including those in daycare through middle school. ${ }^{47}$

All states allow for medical exemptions for children who cannot receive a vaccine or vaccines due to medical contraindications. Most states also offer nonmedical exemptions for either religious or personal beliefs. As previously discussed, parents who refuse immunizations put their children and the community at increased risk for outbreaks of diseases such as measles. Similarly, data from states that offer medical and religious exemptions from school immunization requirements show that these states have lower immunization rates and increased incidence of communicable diseases when compared with states with more rigorous rules. ${ }^{29,48}$ As a means to encourage families to reconsider such decisions and protect themselves, physicians have been encouraged to have parents sign refusal forms acknowledging their responsibility for the decision to leave their child unprotected. ${ }^{49,50}$

Many parents with negative attitudes about vaccines seem to lack accurate information. This lack of information has been associated with negative impressions of medical providers, as well as anxiety regarding immunizing their children. ${ }^{51}$ Ongoing efforts to provide more accurate and timely information to parents in order to alleviate their concerns have achieved modest success. For example, laws mandating the distribution of Vaccine Information 
Statement forms in 1986 were intended to require providers to share consistent information about each vaccine. Educational interventions for providers and parents have been shown to affect parental knowledge and attitudes. ${ }^{34}$

However, some studies have shown that vaccine-related messages need to be customized on the basis of each parent's previous beliefs, a challenge, given the time constraints busy practitioners face. ${ }^{52}$ Combating the misinformation conveyed in the lay press and media presents a welcome opportunity to improve the partnership between parents and the medical community in an effort to improve vaccination rates.

\section{RECOMMENDATIONS}

Despite the evidence that high immunization coverage rates result in protection from vaccine-preventable diseases for individuals and society, the United States continues to struggle to maintain high immunization rates. The process of vaccine development, approval, and recommendation is complicated, but provides internal checks and balances to ensure that there are clear benefits to all potential recipients, with minimal risk (see Sidebar, page 140). In addition, there is a network of vaccine safety monitoring systems designed to detect any evidence of harm. Carefully crafted legislation has created a no-fault compensation system, the VICP, that minimizes individual and industry expenditures on legal action. The VICP maximizes payments to those rare individuals who are harmed by vaccines and promotes continued innovation in vaccine technology and consistent vaccine supply.

Most immunizations are provided through the private sector, rather than as an organized public health initiative. Many providers struggle to provide vaccines, given the high costs involved in purchase and storage and poor reimbursement rates, increasingly choosing to no longer participate in immunization activities. Access to consistent providers is therefore a growing challenge, especially for patients from lower socioeconomic levels.

Although Medicaid and the VFC programs offer vaccine coverage for the most disadvantaged, the growing number of underinsured families presents even greater challenges. Even those who are employed on a full-time basis may have difficulty obtaining vaccines, given the wide variation in employer-based insurance coverage for preventive care. Regulations vary from state to state regarding the responsibilities of insurers for covering immunizations, and the provisions for coverage by public health immunization programs also vary widely by state.

Another barrier to immunization coverage is the increasingly mobile US population. This increased mobility makes data gathering and record keeping a challenging task. Tools to improve immunization services, such as immunization registries, are disconnected and far from universal, while methods such as recall and reminder systems are underutilized.

As disease incidence declines, and the perception that there are potential dangers from vaccines increases, parents are increasingly choosing to leave their children unprotected, endangering not only the children and their immediate families, but the larger community as well. These parental decisions appear to be linked to their lack of understanding of how the 
system works, as well as a lack of appreciation for the role that immunizations had and have in preventing cases of vaccine-preventable diseases.

Finally, there is a vast amount of misinformation conveyed by the mass media and across the internet, which when coupled with the information overload faced by most Americans, makes the provision of accurate information increasingly difficult.

A comprehensive approach to changing the structure and provision of immunization services in the US is needed. New policies are needed that are directed at increasing the perceived value of immunizations across society, while diminishing the systemic and financial barriers for producers, providers and families. Only through a collaborative effort involving public and private healthcare providers, the pharmaceutical industry, public health experts, research scientists, government officials, and the public, will a consistent, stable and financially viable system emerge that will offer safe and effective protection from vaccine-preventable diseases for all members of society.

\section{Acknowledgments}

The project described is supported, in part, by award number T32HD049302 from the Eunice Kennedy Schriver National Institute of Child Health and Human Development. The content is solely the responsibility of the authors and does not necessarily represent the official views of the Eunice Kennedy Schriver National Institute of Child Health and Human Development or the National Institutes of Health.

\section{REFERENCES}

1. Roush SW, Murphy TV; Vaccine-Preventable Disease Table Working Group. Historical comparisons of morbidity and mortality for vaccine-preventable diseases in the United States. JAMA. 2007;298(18):2155-2163. [PubMed: 18000199]

2. Zhou F, Santoli J, Messonnier ML, et al. Economic evaluation of the 7-vaccine routine childhood immunization schedule in the United States, 2001. Arch Pediatr Adolesc Med. 2005;159(12):11361144. [PubMed: 16330737]

3. Healthy People 2010: Understanding and improving health. Washington DC: US Department of Health and Human Services. Available at: www.feddesk.com/freehandbooks/121505-1.pdf Accessed Feb. 22, 2011.

4. Dayan GH, Ortega-Sanchez IR, LeBaron CW, Quinlisk MP; Iowa Measles Response Team. The cost of containing one case of measles: the economic impact on the public health infrastructure - Iowa. Pediatrics. 2004;116(1):e1-e4.

5. Zhou F, Ortega-Sanchez IR, Guris D, Shefer A, Lieu T, Seward JF. An economic analysis of the universal varicella vaccination program in the United States. J Infect Dis. 2008;197 Suppl 2: S156S164. [PubMed: 18419391]

6. Klein JO, Myers MG. Vaccine shortages: why they occur and what needs to be done to strengthen vaccine supply. Pediatrics. 2006;117(6):2269-2275. [PubMed: 16740872]

7. Marshall GS. Vaccine Infrastructure in the United States In: Marshall GS, Denney PH, Greenberg DP, Offit PA, Tan TQ The Vaccine Handbook: A Practical Guide for Clinicians. Professional Communications Inc West Islip, NY 2008:49-86.

8. Smith JC, Snider DE, Pickering LK; Advisory Committee on Immunization Practices. Immunization policy development in the United States: the role of the Advisory Committee on Immunization Practices. Ann Intern Med. 2009;150(1):45-49. [PubMed: 19124820]

9. Cortese MM, Parashar UD; Centers for Disease Control and Prevention (CDC). Prevention of rotavirus gastroenteritis among infants and children: recommendations of the Advisory Committee on Immunization Practices (ACIP). MMWR Recomm Rep. 2009;58(RR-2):1-25. 
10. Harpaz R, Ortega-Sanchez IR, Seward JF; Advisory Committee on Immunization Practices (ACIP) Centers for Disease Control and Prevention (CDC). Prevention of herpes zoster: recommendations of the Advisory Committee on Immunization Practices (ACIP). MMWR Recomm Rep. 2008;57(RR-5):1-30.

11. Centers for Disease Control and Prevention. Recommended Immunization Schedules for Persons Aged 0 Through 18 Years — United States, 2011. MMWR. 2011:60(05);1-4

12. American Academy of Pediatrics Committee on Infectious Diseases. Recommended childhood and adolescent immunization schedules — United States, 2009. Pediatrics. 2009;123(1):189-190. [PubMed: 19117881]

13. Centers for Disease Control and Prevention. General Recommendations on Immunization: Recommendations of the Advisory Committee on Immunization Practices (ACIP). MMWR. 2011: 60(RR02);1-60.

14. Hinman AR, Orenstein WA, Rodewald L. Financing immunizations in the United States. Clin Infect Dis. 2004;38(10):1440-1446. [PubMed: 15156483]

15. Centers for Disease Control and Prevention. CDC Vaccine Price List. www.cdc.gov/vaccines/ programs/vfc/cdc-vac-price-list.htm. Accessed Feb. 14, 2011.

16. Glazner JE, Beaty BL, Pearson KA, Berman S. The cost of giving childhood vaccinations: differences among provider types. Pediatrics. 2004;113(6):1582-1587. [PubMed: 15173477]

17. Light DW, Andrus JK, Warburton RN. Estimated research and development costs of rotavirus vaccines. Vaccine. 2009;27(47):6627-6633. [PubMed: 19665605]

18. Offit PA. Why are pharmaceutical companies gradually abandoning vaccines? Health Aff (Millwood)). 2005;24(3):622-630. [PubMed: 15886152]

19. Luman ET, Barker LE, Shaw KM, McCauley MM, Buehler JW, Pickering LK. Timeliness of childhood vaccinations in the United States: days undervaccinated and number of vaccines delayed. JAMA. 2005;293(10):1204-1211. [PubMed: 15755943]

20. Chu SY, Barker LE, Smith PJ. Racial/ethnic disparities in preschool immunizations: United States, 1996-2001. Am J Public Health. 2004;94(6):973-977. [PubMed: 15249301]

21. Steyer TE, Mainous AG, 3rd, Geesey ME. The effect of race and residence on the receipt of childhood immunizations: 1993-2001. Vaccine. 2005;23(12):1464-1470. [PubMed: 15670882]

22. Geoffard P, Philipson T. Disease eradication: private versus public vaccination. The American Economic Review. 1997;87:222-230.

23. Goldstein KP, Philipson TJ, Joo H, Daum RS. The effect of epidemic measles on immunization rates. JAMA. 1996;276(1):56-58. [PubMed: 8667540]

24. Philipson T. Private vaccination and public health: an empirical examination for U.S. measles. The Journal of Human Resources. 1996;31(3):611-630.

25. Groom AV, Cheek JE, Bryan RT. Effect of a national vaccine shortage on vaccine coverage for American Indian/Alaska Native children. Am J Public Health. 2006;96(4):697-701. [PubMed: 16507733]

26. Bardenheier BH, Yusuf HR, Rosenthal J, et al. Factors associated with underimmunization at 3 months of age in four medically underserved areas. Public Health Rep. 2004;119(5):479-485. [PubMed: 15313111]

27. Holt E, Guyer B, Hughart N, Keane V, Vivier P, Ross A, Strobino D. The contribution of missed opportunities to childhood underimmunization in Baltimore. Pediatrics. 1996;97(4):474-480. [PubMed: 8632931]

28. Smith PJ, Chu SY, Barker LE. Children who have received no vaccines: who are they and where do they live? Pediatrics. 2004;114(1):187-195. [PubMed: 15231927]

29. Omer SB, Pan WK, Halsey NA, et al. Nonmedical exemptions to school immunization requirements: secular trends and association of state policies with pertussis incidence. JAMA. 2006;296(14):1757-1763. [PubMed: 17032989]

30. Salmon DA, Moulton LH, Omer SB, DeHart MP, Stokley S, Halsey NA. Factors associated with refusal of childhood vaccines among parents of school-aged children: a case-control study. Arch Pediatr Adolesc Med. 2005;159(5):470-476. [PubMed: 15867122] 
31. Wakefield AJ, Murch SH, Anthony A, et al. Ileal-lymphoid-nodular hyperplasia, non-specific colitis, and pervasive developmental disorder in children. Lancet 1998;351(9103):637-641. [PubMed: 9500320]

32. Taylor B, Miller E, Farrington CP, et al. Autism and measles, mumps, and rubella vaccine: no epidemiological evidence for a causal association. Lancet. 1999;353(9169):2026-2029. [PubMed: 10376617]

33. Offit Paul A. Autism's False Prophets: Bad Science, Risky Medicine, and the Search for Cure. Columbia University Press New York, NY; 2008.

34. Shefer A, Briss P, Rodewald L, et al. Improving immunization coverage rates: an evidence-based review of the literature. Epidemiol Rev. 1999;21(1):96-142. [PubMed: 10520476]

35. Feikin DR, Lezotte DC, Hamman RF, Salmon DA, Chen RT, Hoffman RE. Individual and community risks of measles and pertussis associated with personal exemptions to immunization. JAMA. 2000;284(24):3145-3150. [PubMed: 11135778]

36. Jansen VA, Stollenwerk N, Jensen HJ, Ramsay ME, Edmunds WJ, Rhodes CJ. Measles outbreaks in a population with declining vaccine uptake. Science. 2003;301(5634):804. [PubMed: 12907792]

37. Peacock G, Yeargin-Allsopp M. Autism spectrum disorders: prevalence and vaccines. Pediatr Ann. 2009;38(1):22-25. [PubMed: 19213289]

38. Centers for Disease Control and Prevention. Measles in a Population with Religious Exemption to Vaccination — Colorado. MMWR. 1985:34(47);718-720. [PubMed: 3932838]

39. Staat MA, Meinzen-Derr J, Welch T, et al. Varicella-related hospitalization and emergency department visit rates, before and after introduction of varicella vaccine, among white and black children in Hamilton County, Ohio. Pediatrics. 2006;117(5):e833-e839. [PubMed: 16651288]

40. Centers for Disease Control and Prevention (CDC). Direct and indirect effects of routine vaccination of children with 7-valent pneumococcal conjugate vaccine on incidence of invasive pneumococcal disease--United States, 1998-2003. MMWR Morb Mortal Wkly Rep. 2005;54(36): 893-897. [PubMed: 16163262]

41. Joyce T, Racine A. CHIP shots: association between the State Children's Health Insurance Programs and immunization rates. Pediatrics. 2005;115(5):e526-34. [PubMed: 15867017]

42. Briss PA, Rodewald LE, Hinman AR, et al. Reviews of evidence regarding interventions to improve vaccination coverage in children, adolescents, and adults. The Task Force on Community Preventive Services. Am J Prev Med. 2000;18(1 Suppl):97-140.

43. Dombkowski KJ, Lantz PM, Freed GL. Role of health insurance and a usual source of medical care in age-appropriate vaccination. Am J Public Health. 2004;94(6):960-966. [PubMed: 15249299]

44. Kempe A, Beaty BL, Steiner JF, Pearson KA, Lowery NE, Daley MF, Crane LA, Berman S. The regional immunization registry as a public health tool for improving clinical practice and guiding immunization delivery policy. Am J Public Health. 2004;94(6):967-972. [PubMed: 15249300]

45. Marshall GS. Standards, Principles, and Regulations. In: Marshall GS, Denney PH, Greenberg DP, Offit PA, Tan TQ The Vaccine Handbook: A Practical Guide for Clinicians. West Islip, NY: Professional Communications; 2008:87-110.

46. Davis MM, Gaglia MA. Associations of daycare and school entry vaccination requirements with varicella immunization rates. Vaccine. 2005;23(23):3053-3060. [PubMed: 15811652]

47. Averhoff F, Linton L, Peddecord KM, Edwards C, Wang W, Fishbein D.A middle school immunization law rapidly and substantially increases immunization coverage among adolescents. Am J Public Health. 2004;94(6):978-984. [PubMed: 15249302]

48. Omer SB, Salmon DA, Orenstein WA, deHart MP, Halsey N Vaccine refusal, mandatory immunization, and the risks of vaccine-preventable diseases. N Engl J Med. 2009;360(19):19811988. [PubMed: 19420367]

49. Diekema DS; American Academy of Pediatrics Committee on Bioethics.Responding to parental refusals of immunization of children. Pediatrics. 2005;115(5):1428-1431. [PubMed: 15867060]

50. American Academy of Pediatrics Childhood Immunization Support Program. Documenting Parental Refusal to Have Their Children Vaccinated. www.aap.org/immunization/pediatricians/pdf/ RefusaltoVaccinate.pdf. Accessed Feb. 22, 2011. 
51. Gust DA, Kennedy A, Shui I, Smith PJ, Nowak G, Pickering LK. Parent attitudes toward immunizations and healthcare providers the role of information. Am J Prev Med. 2005;29(2):105112. [PubMed: 16005806]

52. Keane MT, Walter MV, Patel BI, et al. Confidence in vaccination: a parent model. Vaccine. 2005;23(19):2486-2493. [PubMed: 15752835]

53. Wood DL; American Academy of Pediatrics Committee on Community Health Services; American Academy of Pediatrics Committee on Practice and Ambulatory Medicine. Increasing immunization coverage. American Academy of Pediatrics Committee on Community Health Services. American Academy of Pediatrics Committee on Practice and Ambulatory Medicine. Pediatrics. 2003;112(4):993-996. [PubMed: 14523201] 


\section{EDUCATIONAL OBJECTIVES}

1. Review the process through which vaccines are licensed and recommendations are developed for routine use.

2. Discuss immunization coverage rates.

3. Review possible strategies to improve immunization coverage rates. 


\section{Recommendations to Improve Childhood Immunization Services in the US $^{17,34,53}$}

1. Comprehensive health care for all children, with routinely recommended immunizations provided in a consistent medical home.

2. Adequate reimbursement for immunization services to providers, including both direct and indirect costs.

3. Integrated immunization registries that allow access to records between health systems and between geographic regions.

4. Collaboration between vaccine manufacturers and government to maintain adequate and reliable vaccine supplies.

5. Maintaining an open, transparent system to ensure safe and effective vaccines for children, which will foster and maintain trust among parents, care givers, and medical professionals.

6. Support for ongoing education for health-professionals about vaccinepreventable diseases and vaccine safety.

7. Increasing community participation, education, and partnership in maintaining responsibility for public health, including strengthening of school immunization requirements.

8. Improved monitoring of disease and vaccination coverage.

9. Support for research and development of new or improved vaccines, and improved immunization delivery.

10. Greater transparency surrounding the research and development costs associated with vaccines in order to establish socially optimal policies.

Source: Conway JH. 